Session 3620

\title{
DSP based Space Vector Pulse Width Modulation (SVPWM) control for AC Motor Drives
}

\author{
Wajiha Shireen, Rahul. A. Kulkarni \\ University of Houston
}

\section{Abstract:}

Space Vector Pulse Width Modulation (SVPWM) is an advanced real time control mechanism that can be used to generate balanced three phase ac voltages of the desired magnitude and frequency at the output of an inverter drive system. SVPWM control implemented in real time using a Digital Signal Processor (DSP) controller has the required features of an advanced motor drive system with fast processing capability and flexibility to implement advanced motor control algorithms. This paper presents the SVPWM strategy in context to how it can be implemented using a DSP. The paper will include analytical equations, software flow diagrams and experimental results from a laboratory prototype drive system.

\section{Introduction:}

Advanced motor drive systems used in modern equipment and industrial processes require the following features from a typical motor controller -

- Fast processing to implement advanced algorithms to minimize torque ripple, on line parameter adaptation, precise speed control etc.

- A flexible solution so that future modification can be realized by changing software instead of redesigning a separate hardware platform.

- Capability of generating multiple high frequency, high-resolution PWM waveforms.

- Implementing multiple features using the same controller (motor control, power factor correction, communication, etc.)

- Making the complete implementation as simple as possible (reduced component count, simple board layout and manufacturing etc.).

Space Vector Pulse Width Modulation (SVPWM) is an advanced real time control mechanism that can be used to generate balanced three phase ac voltages of the desired magnitude and frequency at the output of an inverter drive. SVPWM control implemented in real time using a DSP controller has the required features of an advanced motor drive system mentioned above. This paper presents the SVPWM strategy in context to how it can be implemented using a Digital Signal Processor (DSP). The paper will include the analytical 
equations, software flow diagrams and experimental results from a laboratory prototype drive system.

Electric motors are taught very justifiably in almost all Universities along with some basic motor control methods. However, in order to keep pace with the industrial changes, present day Electrical Engineering or Technology students need to know the state of the art motor control methods that are being used in the context of exciting new applications. DSP based systems have become an indispensable part of many modern equipment and industrial processes. The hardware and software aspects of a Digital Signal Processor (DSP) based controller presented in this paper for ac induction motors will make educators aware of the present trend in motor control and help them incorporate changes in the curriculum that will better prepare the students for the current industrial environment.

\section{Space Vector Pulse Width Modulation (SVPWM)}

A three-phase voltage source inverter shown in Figure 1, consists of six power switching devices. For the three phase inverter, there are eight combinations of the ON and OFF states of the upper switches. The state vectors of the inverter line to neutral voltages are shown in Fig. 2. Six of these eight are non-zero base vectors $\left(\mathrm{v}_{1}\right.$ through $\left.\mathrm{v}_{6}\right)$ and two are zero vectors $\left(\mathrm{v}_{0}\right.$ and $\left.\mathrm{v}_{7}\right)$. The six non-zero base vectors are shown as $U_{0}$ through $U_{300}$ in Fig. 2., divides the cycle into six, $60^{\circ}$ wide sectors. Let us assume that an arbitrary voltage $\mathrm{v}^{*}$ is to be generated by the inverter. The desired voltage $\mathrm{v}^{*}$, located in any sector can be approximated as linear combination of the adjacent base vectors $v_{x}$ and $v_{y}$ along with one of the two zero vectors as in Eqn. (1) given below.

$$
v^{*}=d_{x} v_{x}+d_{y} v_{y}+d_{z} v
$$

where $\mathrm{v}$ is the zero vector and $\mathrm{d}_{\mathrm{x}}, \mathrm{d}_{\mathrm{y}}$ and $\mathrm{d}_{\mathrm{z}}$ denote the duty ratios of states $\mathrm{X}, \mathrm{Y}$ and $\mathrm{Z}$ within one PWM cycle. The duty ratios must add up to $100 \%$ of the PWM switching period, i.e.,

$d_{x}+d_{y}+d_{z}=1$

Vector $\mathrm{v}^{*}$ in Fig. 3 can also be written as:

$$
v^{*}=M V_{\max } e^{j \alpha}=d_{x} v_{x}+d_{y} v_{y}+d_{z} v
$$

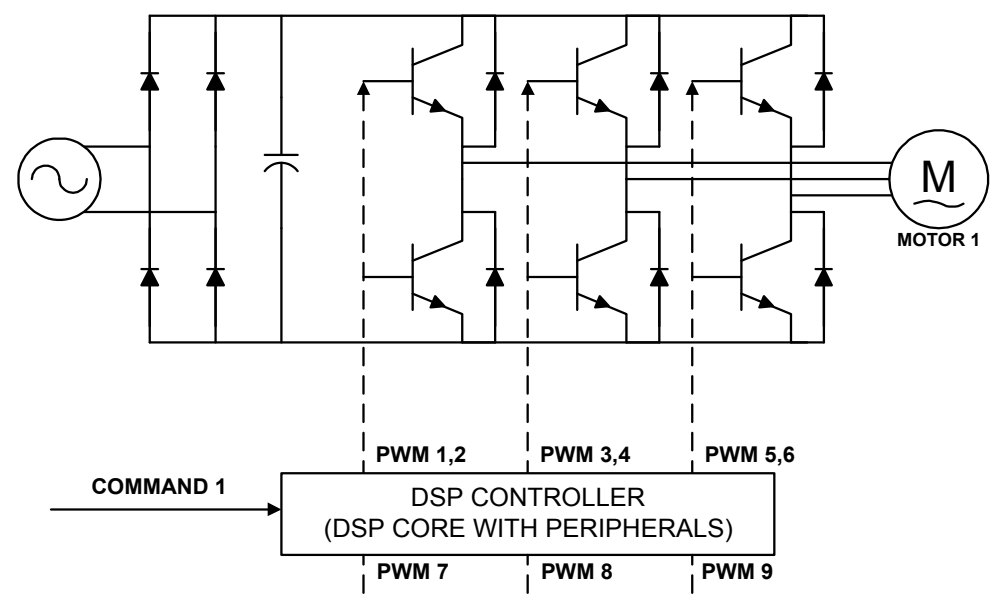

Figure-1 Three-Phase AC Induction Motor Drive 
where, $\mathrm{M}$ is the modulation index and $V_{\max }=\frac{\sqrt{3}}{2} V_{d c}$, is the maximum value of the desired phase voltage.

Taking $\mathrm{V}_{\mathrm{dc}}$ as the base for per unit calculations, the following vectors can be written:

$v_{x}=v_{4}=(1+j 0) p . u ., v_{y}=v_{6}=\left(\frac{1}{2}+j \frac{\sqrt{3}}{2}\right) p . u ., V_{\max }=\frac{\sqrt{3}}{2} p . u$

Substituting the above vectors in Eqn. (3) gives,

$\frac{\sqrt{3}}{2} M \cos (\alpha)=d_{x}+\frac{1}{2} d_{y}, \frac{\sqrt{3}}{2} M \sin (\alpha)=\frac{\sqrt{3}}{2} d_{y}$

Solving for the duty ratios from the above equations yield,

$d_{x}=M \sin \left(60^{\circ}-\alpha\right)$ and $d_{y}=M \cos (\alpha)$

Also, the duration of the zero vector from Eqn. 2 is given by, $d_{z}=1-d_{x}-d_{y}$

The simple algebric formulas Eqns. (6) and (7), allow real-time computation of the duty ratios of the consecutive logic states of the inverter.

\section{System Description}

Figure 1 shows the complete system diagram for a three phase AC Induction motor drive. A three phase voltage source inverter is utilized to operate a three phase AC Induction motor. Six PWM channels from the DSP controller regulate the motor phase voltages by controlling the six power devices of the three phase inverter. This provides the flexibility to vary the motor speed by software means. Space Vector Pulse Width Modulation (SVPWM) is utilized to implement Volts/Hertz (V/Hz) algorithm for the motor drive at different speeds. Both open and closed loop control of the speed of an AC induction motor can be implemented based on the constant $\mathrm{V} / \mathrm{Hz}$ principle. As described in the earlier section, SVPWM refers to a special switching sequence of the upper three power devices of a three phase voltage source inverters used in AC motor drives. This special switching scheme for the power devices results in 3 pseudo-sinusoidal currents in the stator phases. One capture input is utilized to measure the motor speed. A detailed description of the system hardware components including software description is given in the

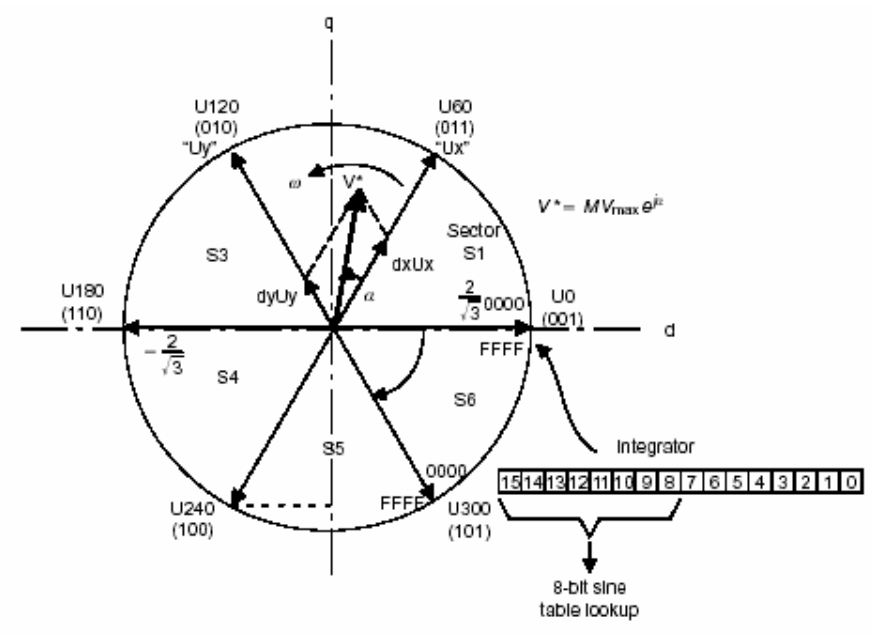

Figure-2 State Vectors of Line to Neutral Voltages 
subsequent sections.

\section{Hardware Configuration}

The experimental system consists of the following hardware components:

- Texas Instruments TMS320F243 EVM platform - The DSP controller is utilized to generate the required PWM outputs based on the $\mathrm{V} / \mathrm{Hz}$ principle at different speeds.

- Spectrum Digital DMC1500 Drive platform - This provides the power stage of the drive system. It consists of a bridge rectifier, DC bus capacitor, a three phase inverter with the associated driver circuitry for the inverter switching power devices (MOSFETs). PWM control signals from DSP Controller are input to the inverter module and output of this module is connected to the motor terminals.

- Spectrum Digital DMC to EVM Interface board

- Three phase AC Induction (ACI) motor.

- IBM compatible development environment including an IBM compatible PC with Code Composer 4.1 or higher installed and XDS510pp emulator.

The complete hardware setup is shown in Figure 3.

\section{Software Description}

The drive system utilizes various software modules for motor control. Figure 4 shows the software block diagram with the various software modules such as RAMP_CNTL, V_HZ_PROFILE, SVGEN_MF and FC_PWM_DRV. Modifying the variable "speed_setpt" can

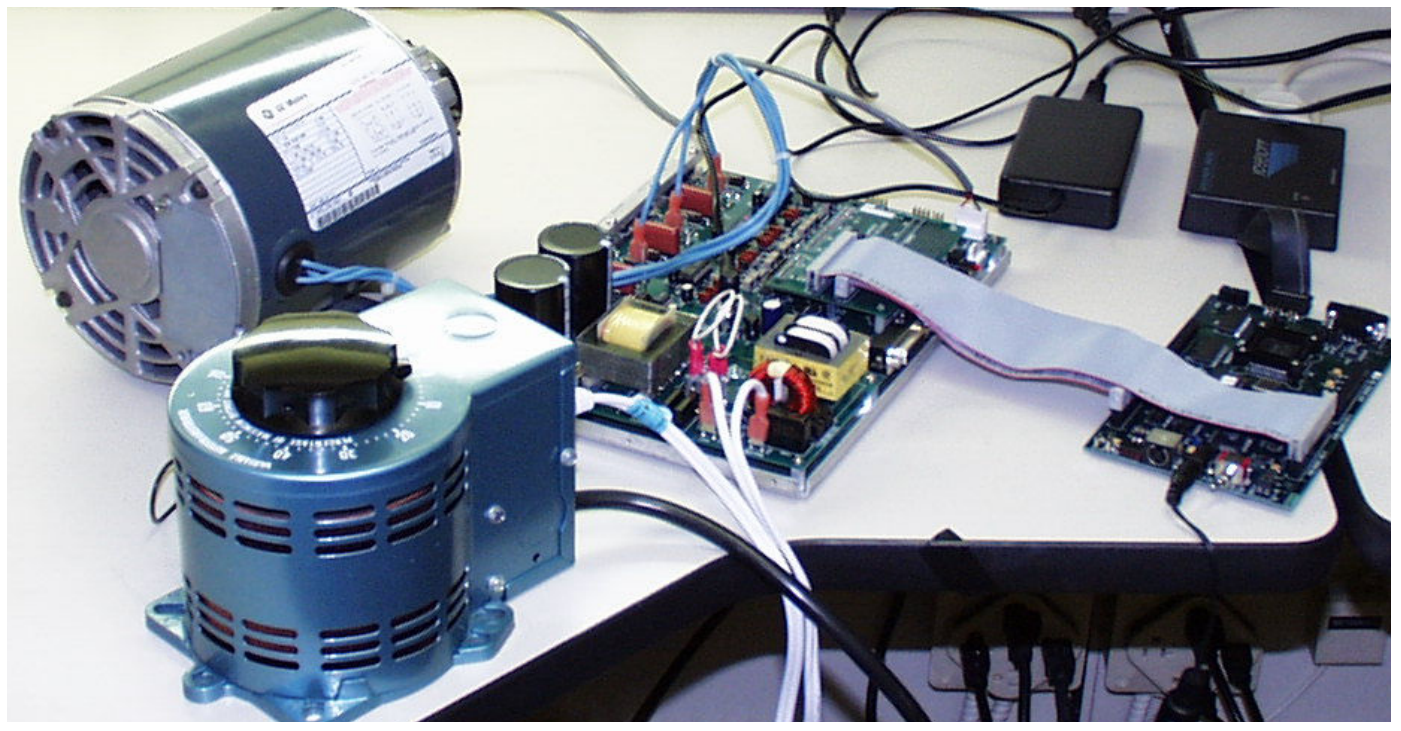

Figure 3 Hardware setup for a DSP controlled three phase AC induction motor drive. 


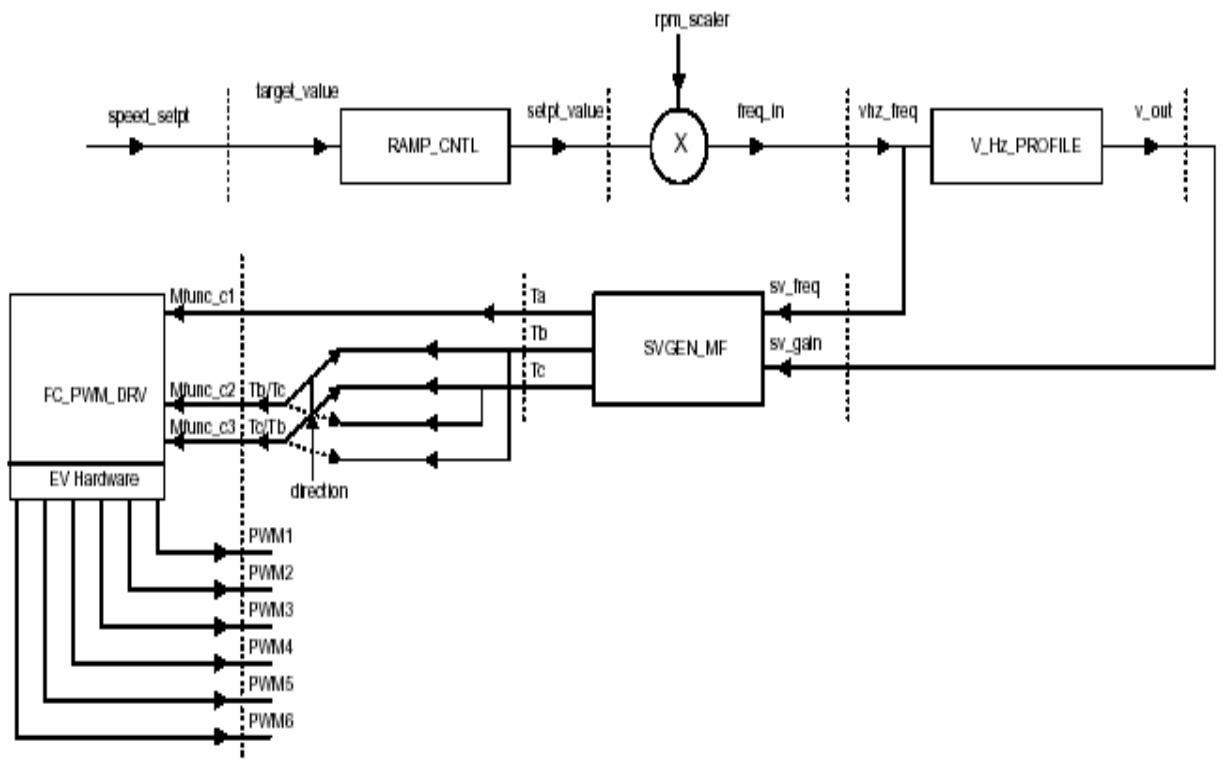

Figure 4 Software Block Diagram

vary the motor speed. The RAMP_CNTL module implements a ramp up and ramp down function. The V_HZ_PROFILE module generates an output command voltage for a specific input command frequency according to the specified volts/hertz profile. This is used for variable speed implementation of AC induction motor drives. The SVGEN_MF module calculates the appropriate duty ratios needed to generate a given stator reference voltage using space vector PWM technique. The stator reference voltage is described by its magnitude (sv_gain) and frequency(sv_freq). The FC_PWM_DRV module uses the duty ratio information and calculates the compare values for generating PWM outputs. It also provides the required dead band to avoid shoot through faults.

\section{Experimental Results}

The ACI motor drive system described above was used to operate a three phase AC

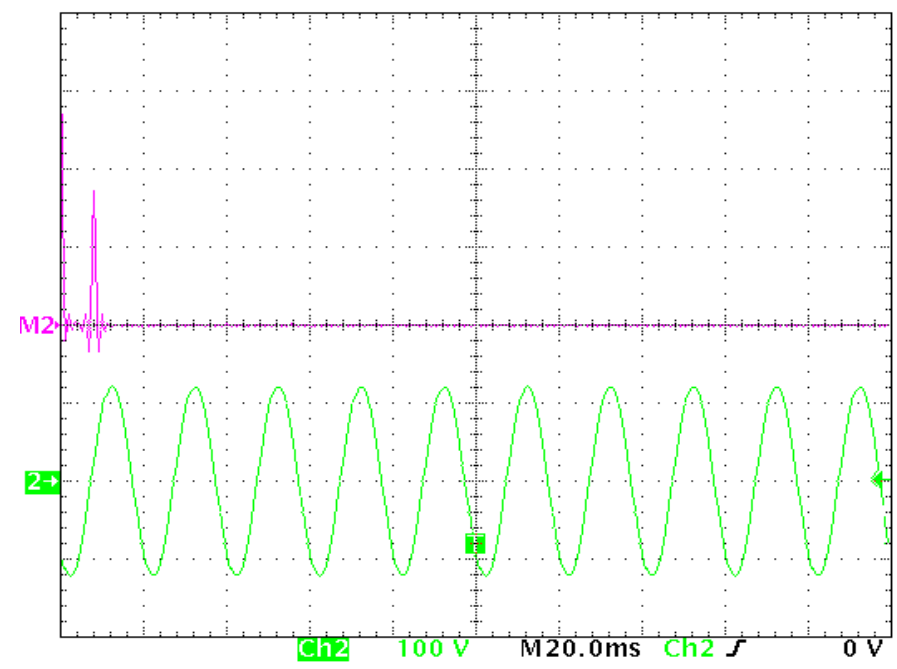

Figure 4 Motor phase current and its frequency spectrum

Proceedings of the 2004 American Society for Engineering Education Annual Conference \& Exposition Copyright (C) 2004, American Society for Engineering Education 
Induction motor with open loop speed control in variable speed mode. The operating frequency was varied between 0 to $60 \mathrm{~Hz}$ and the PWM switching frequency was $20 \mathrm{kHz}$. Figure 4 shows the motor phase current and the corresponding frequency spectrum. From the frequency spectrum of the phase current it can be seen that the motor current consists of the fundamental frequency component and higher order switching frequency harmonics. The $20 \mathrm{kHz}$ SVPWM results in a distortion free phase currents that is used to drive the motor.

\section{Conclusion}

The hardware and software aspects of a Digital Signal Processor (DSP) based controller presented in this paper for ac induction motors will make educators aware of the present trend in motor control and help them incorporate changes in the curriculum that will better prepare the students for the current industrial environment.

\section{References}

1. I Panahi, M Arefeen and Z Yu, "DSP excel in motor-control applications" EDN, pp. 111118, August 15, 1997.

2. M Arefeen, D Figoli and Z Yu, "New generation DSP controllers provide cost effective motion control solutions Power Conversion \& Intellegent Motion, pp. 26-38, February 1998.

3. TMS320F241, TMS320C241, MMS320C242 DSP Controllers - Texas Instruments Inc. www.ti.com.

\section{BIOGRAPHY}

Wajiha Shireen is an Associate Professor in the Engineering Technology Department at University of Houston, Houston, Texas. She obtained her B.S degree in Electrical Engineering from Bangladesh University of Engineering and Technology in 1987. She completed her M.S and PhD degrees in 1991 and 1993, both from Texas A \& M University, College Station, Texas. She joined University of Houston in 1993. Her research interests are in the area of power electronics which includes advanced PWM methods, active power filtering, soft switching inverters etc.

Rahul A. Kulkarni is working towards his M.S degree in Electrical Engineering at University of Houston, Houston, Texas. He obtained his B.S degree from India in 2000. 